\title{
Inês de Castro: da crônica ao mito pela poética da ausência
}

\author{
$\operatorname{pg} 69-79$
}

\section{Resumo}

O presente artigo atende a duas demandas bem demarcadas, sendo que a primeira delas é dar visibilidade ao estágio realizado na Universidade de Coimbra, sob a tutoria do professor Joaquim Braga, com foco na estética da arte e na filosofia. A segunda demanda consistiu em realizar um exercício interpretativo em torno do objeto discursivo de nossa dissertação - Inês de Castro - por meio da noção poética da ausência, que faz parte do arcabouço teórico de Fernando Catroga. A escritura realizada em parceria se deve à caminhada que empreendemos na pesquisa de quem vem de um curso de Arte, faz pós-graduação em Letras e se filia à Análise de Discurso, disciplina de entremeio. Em Inês de Castro, portanto, buscamos pensar como o ausente, constitui-se em presença por meio de manifestações estéticas.

Palavras-chave: Discurso. Memória. História. Poética da ausência. Arte.

\section{INÊS DE CASTRO: FROM THE CHRONICLE TO THE MYTH AND THE POETICS OF ABSENCE}

\begin{abstract}
This article meets two well-demarcated demands, the purpose of the first one is to give visibility to the stage held at the University of Coimbra, under the mentorship of Professor Joaquim Braga, focusing on the aesthetics of art and philosophy. The second demand consisted in performing an interpretive exercise around the discursive object of our dissertation - Inês de Castro - through the poetic notion of absence, which is part of the theoretical framework of Fernando Catroga. The writing done in partnership develops in a research of who comes from an Art course, does post-graduation in Letters and joins to Discourse Analysis, which is among different subjects. In Inês de Castro, therefore, we seek to think how the absentee, constitutes through aesthetic manifestations.
\end{abstract}

Keywords: Speech. Memory. History. Poetics of absence. Art.

1 Mestranda do Programa de Pós-Graduação em Letras da Unicentro, em 2017 realizou inserção na Universidade de Coimbra, sob a tutoria do professor Joaquim Braga. O artigo está na temática da dissertação em desenvolvimento e se insere no projeto: "História, memória e espaço público. Diálogo com Fernando Catroga". Bolsista Capes. emilysmaha@hotmail.com

2 Doutoramento em Filosofia pela Humboldt-Universität zu Berlin, Philosophische Fakultät I, 2010, Licenciatura em Filosofia, Faculdade de Letras da Universidade de Coimbra, 2002. Docente do Instituto de Estudos Filosóficos, da Universidade de Coimbra, Faculdade de Letras. bragajoaquim77@gmail.com - Tutor de Emily Smaha, de setembro a dezembro, na Universidade de Coimbra, do qual este artigo é um dos resultados.

3 Professora Adjunta da Unicentro, orientadora do projeto, de que faz parte este artigo, que se inscreve no projeto "História, memória e espaço público: diálogo com Fernando Catroga”, parte do Estágio Sênior, desenvolvido de fevereiro de 2017 a 31 de janeiro de 2018, na Universidade de Coimbra, sob a supervisão do Prof. Dr. Fernando Catroga. Bolsista Capes, processo BEX 0460/16-3, acordo Araucária/Capes, edital 017/2015. mariacleciventurini@gmail.com 
[...] a representificação é experiência temporal indissociável da sua espacialização. Contudo, esta faceta não se restringe à sua materialidade, pois também forma um campo semântico que garante uma duração e simula a da eternidade - o rito suspende o tempo banal - base necessária para para identificar e perpetuar as mundividências individuais e grupais.

Fernando Catroga

Os passos do homem como restolho do tempo: memória e fim do fim da História)

A necrópole é um livro escrito em linguagem metafórica. Então isto quer dizer que o culto dos mortos, como todo o acto constitutivo de memórias, também é um diálogo imaginário do 'sujeito' consigo mesmo, feito com os olhos, o espirito e o coração, a fim de re-presentificar o evocado.

Fernando Catroga Recordar e comemorar: a raiz tanatológica do ritocomemorativo

\section{Primeiras palavras: entremeios deslocamentos}

Antes de falar de Inês de Castro, o objeto discursivo de nossa pesquisa, é importante destacar as relações entre a história e a ficção e, também o funcionamento do conceito "poética da ausência", de Fernando Catroga, como uma noção relacionada à escrita da história e à representificação do ausente. A escrita da história realiza a re-presentificação do tempo passado (que já não é) e, nos ritos tanatológicos, do morto por meios dos vivos. É importante, também, refletir em torno da poética do saber, de Rancière para entender com mais propriedade as diferenças e as razões para Catroga (2009) e em textos propor a poética da ausência.

A nossa filiação primeira, é na Análise de Discurso, disciplina que se constitui no entremeio entre a Linguística, a Psicanálise e o Marxismo, não se constituindo como um campo interdisciplinar, porque não se 'serve' das demais disciplinas. O objetivo desse trabalho nos 'entremeios' é colocar em suspenso as demais disciplinas. A Análise de Discurso trabalha com o discurso, que

[...] não se reduz ao objeto da Linguística, nem se deixa absorver pela Teoria Marxista e tampouco corresponde ao que teoriza a Psicanálise. Interroga a Linguística pela historicidade que ela deixa de lado, questiona o Materialismo perguntando pelo simbólico e se demarca da Psicanálise pelo modo como, considerando a historicidade, trabalha a ideologia como materialmente relacionada ao inconsciente sem ser absorvida por ele (ORLANDI, 2015, p. 20).

O trabalho que se realiza nas fronteiras permite-nos realizar deslocamentos e convocar a História, a Estética da Arte e a Filosofia para analisar, pela noção poética da ausência, de Fernando Catroga, três materialidades que representam Inês de Castro. A primeira delas refere-se à arte tumular, em que ela está cercada de anjos e coroada rainha; a outra materialidade constitui-se pela capa de um folder e, a terceira, constitui-se da representação do Requiém de Inês de Castro. Especialmente no que concerne à história, convocamos Orlandi (2002, p. 68), para diferenciar a história ciência da história na Análise de Discurso, pois nesse campo disciplinar a história não é aquela que se reflete no texto, mas a historicidade do texto em sua materialidade, constituindo-se como o acontecimento do texto como discurso, "o trabalho dos sentidos nele".

Estruturalmente, este artigo vai se dividir, além da introdução e da conclusão, em mais duas partes: uma primeira em que enfocamos as questões de Estética da Arte, sempre contrapondo à Análise de Discurso, à História e às questões filosóficas e uma segunda parte em que damos mais visibilidade à noção poética da ausência, tal como foi definida por Fernando Catroga (1999, 2009), contrapondo-a com a poética do saber, de Rancière, buscando analisar os três textos-imagens recortados para a realização desse nosso exercício analítico. 


\section{Inês de Castro: representações simbólicas e estéticas}

As obras de arte em torno da figura de Inês de Castro, enquanto mulher vítima de violência que ocorreram, não só pela sua relação amorosa com o Infante D. Pedro, mas também por questões políticas que envolviam Portugal e a Espanha. Segundo Bule (2017, p. 253) “A vida, morte e glorificação de Inês de Castro, acontecimentos que tiveram lugar no Portugal do século XIV, interessaram desde sempre poetas e cronistas portugueses" e desse interesse resultaram diferentes manifestações estéticas que nos permitem interpretar os acontecimentos sob diferentes pontos de vistas estéticos.

Devido à sua história que, a partir da história está registrada, é cercada de incertezas, segundo Asênsio (1965, p. 337) destaca “[...] que de los documentos salió una Inés imperfecta, anecdótica, en la forja de las crónicas fué liberándose de sus tachas e impurezas y en el crisol de la poesia acabó transformada en una figuración del triunfo del amor sobre la muerte, en un mito radiante".

Essa figura anedótica e imperfeita referida por Asênsio talvez se deva ao fato de os registros históricos das mulheres na Idade Média não terem importância, assim como, os interesses políticos da época não considerarem Inês de Castro relevante, além do que os registros se constituíam de anotações. Sendo assim, as diferentes artes perpetuaram a relação que ambos tiveram, influenciando dessa forma os modos de observar e de interpretar os espaços na cidade de Coimbra e de Alcobaça, os quais foram cenários deste romance. Podemos considerar as diferentes representações, como funções sociais que serviram como suporte para a construção da cultura em torno do imaginário sobre Inês. A representação, conforme destaca Langer tem
[...] a função de dirigir a mente de quem percebe para algo além da obra de arte, a saber, o objeto ou ação representado: ou pode ser considerada como o objeto ou ação representado: ou pode ser considerada como o motivo que o artista tem para criar a obra - um resgistro de coisas que o fascinam, pessoas ou coisas que ele deseja imortalizar. (LANGER, 1953, p.16).

Estas manifestações fizeram com que o imaginário sobre ela continuasse com o tempo sendo disseminada em diferentes meios. Podemos considerar sua história como um mito, se levarmos em consideração que o mito aparece em primeiro como caos, com ideias que não fazem sentido, sem rima e razão (CASSIRER, 1944). A história de Inês e Pedro se encaixa nesta definição, pois não apresenta uma única interpretação, mas diferentes narrativas que atravessaram a história por diferentes manifestações poéticas.

Além de considerarmos a sua trajetória como mito nas diferentes artes, se faz importante também observar como os símbolos estão presentes nas materialidades, segundo Braga:

[...] os símbolos estão indissociavelmente ligados à sensibilidade. Logo, o trabalho da expressão vai evidenciar quer a exteriorização elemento significativo quer a preparação de um elemento significativo quer a preparação de um elemento significante, estando neste sentido, dependente das condições materiais que possibilitam a organização sensível da forma que incopora. (BRAGA, 2014, p.19)

Com isto, sinalizamos que nas obras de arte, por meio da observação sensível é possível entender a constituição da significação e dos sentidos, bem como a construção das relações. Cassirer (1944, p. 98), nos diz que: "There is no natural phenomenon and no phenomenon of human life that is not capable of a mythical interpretation, and which does not call for such an interpretation ${ }^{4 \prime}$. Disso, é possível afirma que a humanidade em si, em suas diferentes relações está passível de receber influências míticas, que auxiliam na compreensão 4 "Não há fenômeno natural e nenhum fenômeno da vida humana que não seja capaz de uma interpretação mítica e que não exige essa interpretação.” Tradução nossa. 
dos fatos relacionados à suas origens, formações sociais e históricas. De acordo com Braga (2014, p.13): "Compreender as formas de expressão culturais é implicar os processos de simbolização na criação e apreensão da realidade.” Assim, se faz relevante o estudo de como o mito inesiano em diferentes manifestações contribuiu para a concretização destes diferentes símbolos e auxiliou no entendimento sobre a formação cultural e a permanência simbólica secular, envolvendo o mito.

A possibilidade de análise destas manifestações contribui para o entendimento do mito, do símbolo e da formação da cultura, pois: "Na concepção de Ernst Cassirer, a ideia de cultura só pode ser analisada a partir das múltiplas formas de mediação culturais.” (BRAGA, 2014, p. 13-14)

Tendo em vista que as manifestações artísticas inesianas foram construídas a partir do pressuposto de que Inês de Castro é um mito e, devido à necessidade de compreender os processos simbólicos em obras de arte com temáticas inesianas adentramos na Filosofia, a qual segundo Cassirer (1944), contribui para desmascarar o mito, se o seu significado se esconde por meio de símbolos e imagens. Além da relevância dos estudos filosóficos para a interpretação, podemos observar, por meio dos estudos do filósofo, que:

The mythical world appears as an artificial world, as a pretense for something else. Instead of being a belief, it is a mere make-believe. What distinguishes these modern methods from the earlier forms of allegorical interpretation is the fact that they no longer regard myth as a mere invention made for a special purpose. Though myth is fictitious, it is an unconscious, not a conscious fiction ${ }^{5}$. (CASSIRER, 1944, p.99).

5 "O mundo mítico aparece como um mundo artificial, como uma pretensão para outra coisa. Em vez de ser uma crença, é uma mera criatividade. $\mathrm{O}$ que distingue esses métodos modernos das formas anteriores de interpretação
Ou seja, por mais que consideremos muitas das narrativas apresentadas sobre a história de Inês como ficção, não alicerçadas no documento e na veridicção, como é recorrente quando se trabalha também na história, não há como esquecer que as narrativas que romanceiam a sua coroação depois de morta e mistificam a Fonte dos Amores, localizada na Quinta das Lágrimas, como tendo sido o palco da sua morte. Ainda assim, estas manifestações e histórias continuam sendo perpetuadas por uma memória construída por meio de diferentes expressões da linguagem.

A partir dessas considerações, o mito relaciona-se com a veridicção. Ele é uma ficção inconsciente e, constitui-se por processos memorialísticos, históricos e mantém o mito significativo até os dias de hoje, nas produções artísticas e nas narrativas que se travestem de efeitos de verdade. O mito inesiano apropriou-se das capacidades e dimensões das esferas artíticas pois,"combines a theoretical element and an element of artistic creation"'. (CASSIRER, 1944, p. 100-101) e isto, no corpus em análise pode ser visualizado, pois sua trajetória secular mostra a sua materialização e reinvenção, com elementos simbólicos que evidenciam a criação artística, a criatividade e elementos de sua narrativa mitológica, que fogem dos textos ditos verdadeiros, advindos do registro histórico.

alegórica é o fato de que eles não consideram o mito como uma mera invenção feita para um propósito especial. Embora o mito seja fictício, é uma ficção inconsciente, não consciente." Tradução nossa.

6 "Combina um elemento teórico e um elemento de criação artística." Tradução nossa. 

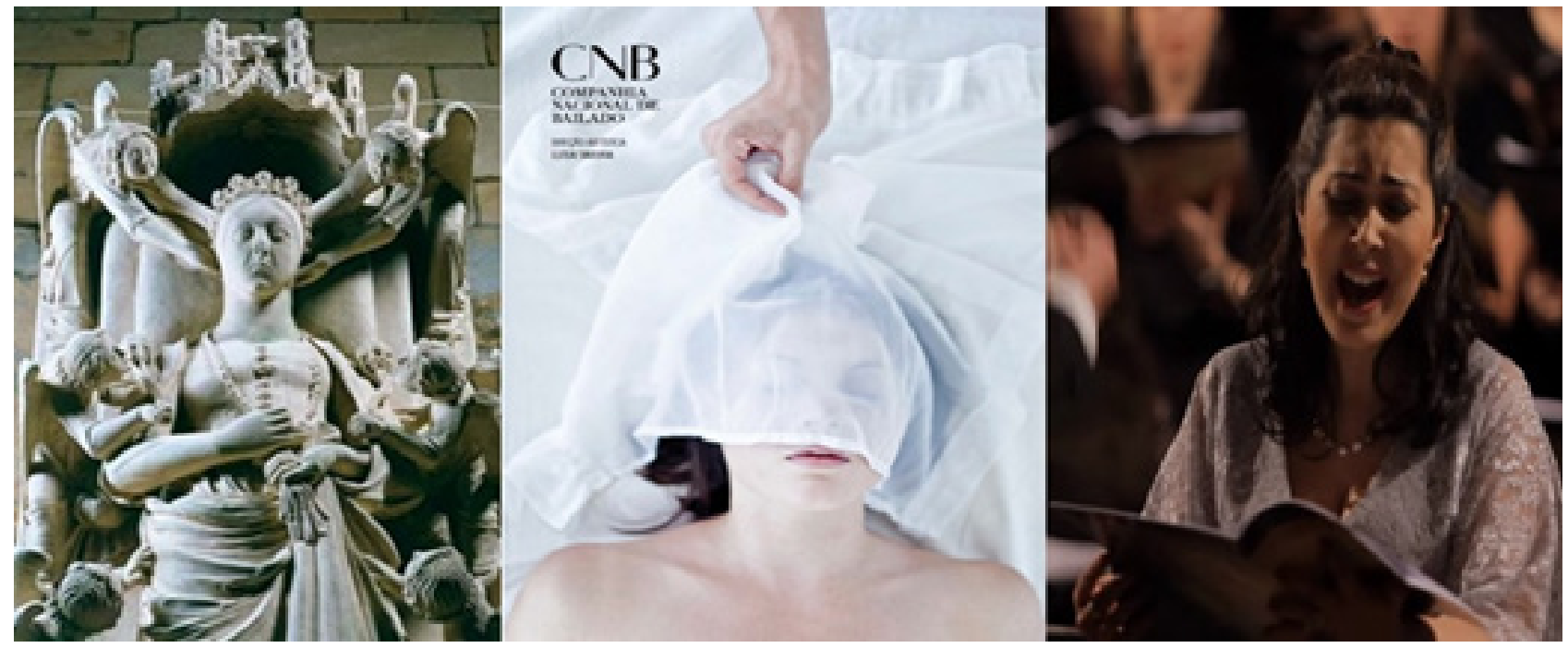

Conjunto de textos-imagem: 1: Túmulo Escultural; 2: Capa do Folder; 3: Soprano Fonte: Wikipedia; Missed in History; Youtube.

No conjunto de textos-imagens acima há três materialidades, nas quais o discurso inesiano apresenta-se por meio de manifestações poéticas distintas. No primeiro texto-imagem, à esquerda, com a representação do corpo de Inês, coroada como rainha de Portugal e rodeada por anjos, no seu túmulo escultural, situado no mosteiro de Alcobaça. O túmulo foi esculpido entre os anos de 1358 e 1367 no estilo gótico, por ordem do rei D. Pedro, sua autoria é desconhecida. O segundo texto-imagem faz parte da capa do folder distribuído no espetáculo de dança Pedro e Inês, produzido pela Companhia Nacional de Bailado e dirigido por Olga Roriz, em 2012 e reapresentado em 2015, na Europa e no Brasil. E, por fim o último texto-imagem é um registro da apresentação do Requièm Inês de Castro, em 2012, composto por Pedro Camacho, em que a soprano interpreta a figura de Inês.

Há necessidade de dar a ver, de início, que o mito inesiano presente nas esferas artísticas, que dele se apropriaram, como bem demonstra o conjunto de textos-imagens mais acima. A escultura, a dança e a música, contrapondo uma esfera do século XIV a outras duas manifestações do século XXI. Essas três manifestações dão visibilidade ao modo como a memória de Inês de Castro, ultrapassou séculos e foi reinventada por meio de manifestações simbólicas em manifestações artísticas distintas. Trata-se, da re-presentificação de um passado ausente, o qual de acordo com Catroga (2009, p.131), dando voz aos apelos "vindos do passado, que solicitam futuros que só o presente, ou melhor, o cruzamento entre memória e expectativa poderá esculpir". É assim que essas materialidades de arte podem ser analisadas pela noção poética da ausência, pois assim como a historiografia, no muito que dá a conhecer, muito cai no esquecimento, assim como ocorre com "os passos do homem", cujos rastros, muitas vezes se apagam.

Vale destacar que a fusão entre mito e arte nas manifestações artísticas inesianas, mostram a relação do mito com a linguagem pois: "In the early of human culture their relation is so close and their cooperation so obvious that it is almost impossible to separate the one from the other."' (CASSIRER, 1944, p.142). O mito, apesar da ausência é presença, desde há muito tempo nas formas de expressão da humanidade, mostrando as relações, principalmente, com as diferentes comunicações nos aspectos históricos, memorialísticos e artísticos. Nesse funcionamento, está a relevância

7 "No início da cultura humana, sua relação é tão próxima e sua cooperação tão óbvia que é quase impossível separar uma da outra." Tradução nossa. 
do mito para a compreensão de sua ligação com as diferentes manifestações de arte, as quais ocorrem porque "Whenever we find a man we find him in possession of the faculty of speech and under the influence of the myth-making function"s (CASSIRER, 1944, p. 142).

Nessa perspectiva, a língua e a arte, são apropriadas pelo mito e por formações simbólicas nos diversos tipos de manifestações, nas quais, conforme Cassirer (1944) há destaque para a oscilação entre dois polos distintos: o real e o subjetivo. Nos três textos-imagens em análise, há construções pelas quais é possível encontrar relações objetivas e outras dissociadas/desvinculadas da realidade. Porém, ainda segundo o autor, nenhuma teoria da arte pode esquecer ou suprimir nenhum destes polos, podendo-se destacar que ambos são confluentes, e nenhum é determinante sob alguma manifestação artística. As obras inesianas sinalizam para a presença do subjetivo e do real e encaminham para a presença do ausente, por meio das obras estéticas que fazem do tema um tema português na Europa, segundo Sousa (2005).

A análise da construção do mito por meio da simbolização atribuída à figura de Inês de Castro é observada em sua totalidade, devido ao princípio de que:

Uma obra de arte é um símbolo indivisível,
único, embora seja um símbolo altamente
articulado; não é, como um discurso (que
também pode ser considerada como uma
forma simbólica única), composto analisável
em símbolos mais elementares - sentenças,
orações, frases, palavras e mesmo partes
separadamente significativas de palavras: raízes,
prefixos, sufixos, etc. (LANGER, 1953, p. 383).

$\mathrm{Na}$ representação dos momentos finais da história entre Pedro e Inês, vemos, a construção de um imaginário sobre o trágico fim, e o momento da morte e pós-morte de Inês. Para que isto seja materializado em diferentes formas, enfocamos a

8 "Sempre que encontramos um homem, o encontramos em posse da faculdade de expressão e sob a influência da função de criação de mitos" Tradução nossa. função mimética, sob a categoria da imitação, tendo em vista que ambas se fazem presentes na Arte e na Língua, pois "Language originates in an imitation of sounds, art is an imitation of outward things. Imitation is a fundamental instinct, an irreducible fact of human nature". ' (CASSIRER, 1944, p. 177).

Tendo em vista que a imitação é indissociável da natureza humana, vemos que a arte está intrinsicamente associada a este conceito. Entretanto, a imitação não é uma mera representação de acontecimentos, mas um modo de dar visibilidade, por meio de formas simbólicas, à realidade que pode ou não ser conhecida sob um outro modo de reflexão. A função da arte não está em registrar e apresentar o real. De acordo com Cassirer, "We do not, however, discover nature through art in the same sense in which the scientist uses the term 'nature"'. ${ }^{10}$ (CASSIRER, 1944, p. 183). As discussões sobre os temas motivadores da arte, não devem ser considerados apenas pelo que o real nos diz, mas sim, por todo seu contexto subjetivo, o qual o artista apresenta na materialidade escolhida.

Podemos considerar também que: "Cada forma simbólica representa um modo singular de articular e observar as experiências humanas, já que os seus elementos estruturantes não se deixam reduzir a uma mera função indexical, a uma relação contingente entre signo e o objecto." (BRAGA, 2014, p. 15). Neste caso, as manifestações inesianos possuem singularidades que pertencem a formação cultural a qual não deverá ser vista apenas meramente como um sistema de descodificação semântico, mas sim marcados pelo sensível. Langer afirma que:

A crítica de arte não é ciência, porque não está preocupada com a descrição e previsão de fatos. Mesmo que suas premissas fossem

9 "A linguagem se origina em uma imitação de sons, a arte é uma imitação de coisas externas. A imitação é um instinto fundamental, um fato irredutível da natureza humana". Tradução nossa.

10 "No entanto, não descobrimos a natureza através da arte no mesmo sentido em que o cientista usa o termo 'natureza". Tradução nossa. 
claras e coerentes, e eficientes os seus termos, ela permanece uma disciplina filosófica, pois todo seu objetivo é a compreensão. (LANGER, 1953, p. 9).

Se nem a crítica tem o intuito de descrever os fatos, se faz necessário realmente a busca pela compreensão simbólica, cultural e mítica das formas que formam a arte. Segundo Cassirer (1944, p. 184) "Language and science are abbreviations of reality; art is an intensification of reality. Language and science depend upon one and the same process of concretion" $" 11$. Portanto, as manifestações artísticas não apresentam realidades, mas a recriação delas, do que decorrem diferentes modos de interpretálas. Assim, podemos pensar na relação da arte com o mito e na formação de um inconsciente coletivo, responsável pela crença naquilo que está sendo representado. A dependência da humanidade no mito para conseguir se expressar, se justifica devido a:

\footnotetext{
Mankind could not begin with abstract thought or with a rational language. It had to pass through the era of symbolic language of myth and poetry. The first nations did not think in concepts but in poetic images; they spoke in fables and wrote in hieroglyphs. ${ }^{12}$ (CASSIRER, 1944, p.196)
}

Tendo em vista, que em algumas manifestações artísticas a humanidade não se desvincula da linguagem simbólica, do mito e da poesia, o artista por meio de suas obras, se torna o mediador e o responsável por possibilitar àqueles que presenciam e visualizam seus trabalhos, a entrarem em contato com a seleção de processos realizados. Diante da contemplação de obras de arte, somos convidados a olhar determinado aspecto

11 "A linguagem e a ciência são abreviaturas da realidade; A arte é uma intensificação da realidade. A linguagem ea ciência dependem de um mesmo processo de concretização." Tradução nossa.

12 "A humanidade não podia começar com o pensamento abstrato ou com uma linguagem racional. Tinha que passar pela era da linguagem simbólica do mito e da poesia. As primeiras nações não pensaram em conceitos, mas em imagens poéticas; Eles falaram em fábulas e escreveram em hieróglifos." Tradução nossa. do mundo da forma que o artista o construiu, "It would seem as if we had never before seen the world in this peculiar light."'13 (CASSIRER, 1944, p. 187). Porém, é preciso atentar para o modo de interpretá-los porque "We cannot understand the work of art by subjecting it to logical rules. A textbook on poetics cannot teach us how to write a good poem"14, (CASSIRER, 1944, p. 205). Por isso, compreender a arte por maneiras lógicas, tornase superficial e inadequado, tendo em vista que de acordo com Catroga (2009) a ficção não tem compromisso com o referente e com a veridicção.

A imaginação faz parte das obras de arte e, também da história, só que na disciplina que se representa como ciência, há a busca do documento, como possibilidade de comprovar a veracidade do acontecido. Se formos, analisar as obras inesianas, apenas em busca da comprovação e de assimilação entre fatos históricos e as representações, estaremos ignorando as formas de subjetividade que a arte propõe, além de ignorarmos as relações com a realidade, e como isto foi intensificado. É necessário entender a arte além da sua relação com os fatos da realidade. Segundo Braga, devemos

\begin{abstract}
Aceitar a ideia de que as formas artísticas não são meros produtos de transferências e projecções das emoções puras do artista, como é sugerido pelas teorias estéticas de Benedetto Croce e Robin George Collingwood, nem tão-pouco simples manifestações figurativas desprovidas de qualquer sentido expressivo, proporciona, de igual modo, uma verdadeira visão das possibilidades abertas pela obra de arte no que à consciência da formação simbólica da cultura diz respeito, nomeadamente de todas aquelas possibilidades intrínsecas à passagem da participação cultural para a observação cultural. (BRAGA, 2014, p. 25, grifos do autor).
\end{abstract}

Além de considerar esta nova forma de leitura, destacamos que "O mito como forma simbólica é analisado por Cassirer não com um mero intento classificatório do primitivo [...] mas como um ponto

13 "Parece que nunca tínhamos visto o mundo nesta luz peculiar". Tradução nossa.

14 "Não podemos entender o trabalho de arte submetendo-o a regras lógicas. Um livro sobre poética não pode nos ensinar a escrever um bom poema". Tradução nossa. 
de partida seguro para a compreensão da formação das dinâmicas culturais.” (BRAGA, 2014, p.27) O mito inesiano, na arte, nos possibilita discutir a importância das representações para a construção da memória e da ressignificação durante o tempo. A arte faz com que a realidade, os espaços, e os símbolos que nos remetem a tal mito, sejam vistos de uma maneira poética, encaminhando para o gerenciamento de reflexões acerca de determinada temática. A presença do mito na elaboração das linguagens se fez desde muito cedo, a partir da arte presente, juntamente com a língua e o mito. Com isso, foi possível presenciar formas artísticas distintas, as quais promoveram os mais diferentes deleites. Devido a estas experiências, durante toda a história da humanidade a arte possibilitou fugas e novas percepções da realidade, podendo-se dizer que:

\begin{abstract}
Art, on the other hand, teaches us to visualize, not merely to conceptualize or utilize, things. Art gives us a richer, more vivid and colorful image of reality, and a more profound insight into its formal structure. It is characteristic of the nature of man that he is not limited to one specific and single approach to reality but can choose his point of view and so pass from one aspect of things to another. ${ }^{15}$ (CASSIRER, p.216-217).
\end{abstract}

Desse modo, destacamos que os diferentes pontos de vista sobre a história de Pedro e Inês nos permitem o contato com distintas formas da sensibilidade, refletindo sobre elementos que ressoam tanto em relação ao tempo atual, como em relação ao passado, dando a esse passado, como sinaliza Catroga (2009, p. 116) 'futuros'. Esse modo de constituir atemporalidade prospectiva a partir do passado faz retornar memórias e discursos que re-presentificam o ausente, nesse caso, a mulher assassinada por ter contrariado o poder instituído

\footnotetext{
15 "A arte, por outro lado, nos ensina a visualizar, não meramente conceituar ou utilizar, as coisas. A arte nos dá uma imagem mais rica, mais vívida e colorida da realidade, e uma visão mais profunda da sua estrutura formal. É característico da natureza do homem que ele não se limita a uma abordagem específica e única da realidade, mas pode escolher seu ponto de vista e assim passar de um aspecto das coisas para outro". Tradução nossa.
}

da época. A arte aproxima os sujeitos que vivem na sociedade moderna, da realidade medieval, presentificando o passado, seja pela continuidade e ressignificações da história, ou pela observação de crimes, envolvendo mulheres mortas sem piedade, pelo mesmo motivo.

\section{Inês de Castro pela noção poética da ausência, de Fernando Catroga}

\section{Para Marcelino (2017, p. 130) “as} comparações entre a historiografia e as práticas de natureza tanatológica, sintetizadas na fórmula 'poética da ausência', podem ser confrontadas com proveito com aquilo que Jacques Rancière chamou de "poética do saber". A poética do saber, tal como concebida por Rancière, visava a abranger a literatura como arte, na qual a língua não era normatizada por regras e não tinha compromisso com a veridicção ou com o referente. A poética do saber, portanto, ocupa-se da invenção, "para a frase histórica, de um regime novo de verdade, produzido pela combinação da objetividade do relato e a certeza do discurso" (RANCIÈRE, 1994, p. 23). Esse novo regime de verdade carrega uma marca de identidade e um nome próprio que liga as palavras às coisas, por meio de um conjunto de procedimentos. O interesse dessa poética recai sobre as regras, segundo as quais "um saber se escreve e se lê, se constitui como um gênero de discurso específico" (RANCIÈRE, 1994, p. 15).

Diferentemente, a poética da ausência, segundo Catroga (2009, p. 39), aproxima túmulo e cemitério, enquanto "totalidades significantes que articulam dois níveis bem diferenciados: um invisível e outro visível [...]" e o nível invisível dissimula a degradação do tempo e aos mesmo tempo simula a não morte, possibilitando a individuação e ajudando na re-presentação, ou a re-presentificação do ausente. $\mathrm{O}$ autor defende a premissa de que a sepultura e os códigos que re- 
presentificam o ausente se constituem com uma forma de fazer presente quem não existe mais e, quanto mais o morto for lembrado, mais a história vai avançar. A mesma noção pode ser aplicada à escrita da história, como forma de tornar presente ou ausente e de lutar contra o esquecimento.

Inês de Castro e as três materialidades estéticas selecionadas para as análises dão visibilidade a uma mulher que em vida não teve vOz e que teria sido esquecida, assim como foram as outras amantes de D. Pedro, caso não tivesse ocorrido a sua morte trágica e o desejo político dele de mostrar que Castro não era culpada. Depois de morta, conforme o texto-imagem $\mathrm{n}^{\circ}$ 01, ela foi coroada rainha. Apesar das narrativas que falam do beija-mão do cadáver, segundo Vasconcellos (2005), essa coroação foi simbólica e constitui efeitos de sentidos de presença de um ausente, de quem, conforme Catroga (2009) já não existe mais, porque não tem um referente. Trata-se de uma ficção, tangenciada pela imaginação estética e que se concretiza por meio da narrativa em forma de esculturas, no monumento tumular. Os anjos representados nesse texto-imagem significam rainha Inês, como rainha e, ao mesmo tempo, fazendo parte de uma política de legitimação da mulher, desencadeada, segundo Coelho e Rebello, por D. Pedro. Podemos ler, também, o monumento tumular sinaliza para o atravessamento do discurso religioso, especialmente, pela presença dos anjos e pela crença de que haverá uma ressureição.

O segundo texto-imagem é, assim como o primeiro, um modo de re-presentificar o ausente. A linguagem plástica e as relações decorrentes da estrutura do texto-imagem permite signifiquemos essa materialidade, atualizando-a, pois não se trata de uma representação fiel, mas de uma simulação, que dissimula a ausência. Entendemos que há uma atualização, pois essa materialidade é de outra época, do que se pode dizer que se trata de uma Inês estilizada.
A soprano que faz ressoar Inês de Castro no terceiro texto-imagem precisa ser olhado com mais atenção, tendo em vista a necessidade, nesse caso, de 'olhar' também para o que está fora dessa materialidade, pois assim será possível colocar lado a lado, a materialidade verbal e a não-verbal, com vistas a identificar o que está dito e, também os não ditos e o que fica a dizer.

\section{Efeito de fechamento}

Transitamos em mais de um campo discursivo e, esse andar pelos 'entremeios' exige a nossa atenção, encaminhando-nos para a criticidade e exigindo seriedade para não fazer retorno um ausente muito diferente daquele que foi presença e que não existe mais em sua forma real, mas como um passado que ganha 'futuros' por meio da recordação.

Quanto à poética da ausência e a poética do saber, entendemos que Catroga busca refletir sobre a história e a historiografia por meio de textualidades em que ressoam o ausente, que se torna presença, pelo lugar ocupado por esse sujeito no imaginário popular. O historiador não deixa de destacar sempre a diferença entre a história e a ficção, sublinhando sempre que a história, enquanto ciência, não prescinde da imaginação, porque o acontecimento, mesmo tendo referente, situa-se no passado e é analisado a partir do presente, a partir de horizontes de expectativas e, assim, como na Análise de Discurso, realiza-se a partir de sujeitos ideológicos. Catroga significa a narrativa sempre filiada a evocadores e a evocados, portanto permeada pela individualidade e pela subjetividade. De qualquer forma, reconhece e defende que o homem, seja o evocador ou o evocado, constitui-se na alteridade e sempre se inscreve a um lugar e a um tempo, no qual há interesses e funcionamentos do poder. 
No que tange às poéticas destacamos que Rancière (1994) - poética do saber - centra-se na indeterminação do discurso histórico constituído na tensão entre as humanidades literárias e a história relacionada ao fazer científico, comprometida com o referente e com a verdade. A poética do saber a partir de Rancière, assim como em Catroga, invoca e discute a linguagem. A diferença está no foco, pois o primeiro questiona a dissipação do discurso e a sintaxe pela qual o acontecimento se transforma em discurso, polemizando a falta de referentes e o excesso de palavras dadas pela homonímia, enquanto o segundo discute a linguagem e a semiótica em que os significantes são procedimentos que fazem do ausente presença, pela linguagem e por meio de símbolos. Catroga relaciona a história à morte, fazendo uma analogia com o túmulo. Para ele o morto já não existe e o tempo da história, também não, porque a história ocorre no passado e é escrita pelo presente, há que fazê-la presença, mesmo não existindo o referente. Tanto o morto como o passado, afinal, já não existem.

Para concluir, resta-nos destacar que o exercício de escrita realizado, nesse artigo, se constituiu em um desafio bastante relevante, tendo em vista a interface entre domínios disciplinares e entre teorias bastante distintas, mas certamente com muitas convergências. Colocamos em um mesmo lugar Cassirer, Langer, Braga, Catroga, Rancière, Orlandi e outros pesquisadores. Dentre as dificuldades detectadas sublinhamos os procedimentos distintos de cada um deles, as prioridades teóricas e, especialmente, os horizontes de expectativas, pois enquanto a estética prioriza o belo e os efeitos não relacionados à veridicção, a história busca sempre o referente. De qualquer modo, há sempre um ausente e, nesse artigo, nos diferentes campos e domínios que invocamos. Convocamos o ausente a partir de Inês de Castro, personagem que a História significa como sem muitos referentes ou modos de buscar saber o que é da ordem do verossímil e do que foi discursivado a partir da crônica e da lenda, elevando-a, a mito. Se na história há poucos documentos sobre Inês de Castro, nas artes ela é elevada a musa, desde Camões. De acordo com os historiadores, foram sempre acrescentados detalhes, ao sabor dos tempos e de interesses sócio-históricos. A sua condição de mito, é preciso dizer, partiu de um fato real, que deu lugar à contradição.

\section{Referências}

BRAGA, Joaquim. Símbolo e Cultura. $1^{\mathrm{a}}$ ed. Grácio Editor: Julho de 2014. Coimbra.

BULE, Lara Miguel. Os amores de Pedro e Inês. Inspiração histórica e Naturalismo na pintura portuguesa oitocentista. Revista de História da Sociedade e Cultura, Coimbra: Imprensa da Universidade de Coimbra, v 17, 2017, p. 253-279.

CASSIRER, Ernst. An essay on man: an introduction. Doubleday \& Company, Garden city, New York, 1944.

CATROGA, Fernando. O céu da memória: Cemitério Romântico e Culto Cívico dos Mortos em Portugal (1756-1911). Coimbra: Livraria Minerva Editora, 1999.

Os passos do homem como restolho do Tempo. Memória e fim do fim da História. Coimbra, Edições Almedina, 2009.

O culto dos mortos como uma poética da ausência. ArtCultura, Uberlândia, v. 12, n. 20, p. 163-182, jan.-jun. 2010.

Recordar e comemorar. A raiz tanatológica dos ritos comemorativos. Mimesis, Bauru, v. 23, n. 2, 2002, p. 13-47.

COELHO, Maria Helena da Cruz e REBELO, António Manuel Ribeiro. D. Pedro e D. Inês: diálogos entre o amor e a morte. "Sermão nas exéquias de 
D. Inês de Castro" de D. João de Cardaillac. Edição crítica, tradução e comentário Filológico. Coimbra: UC, 2017.

LANGER, Susanne K. Sentimento e Forma. Tradução: Ana M. Goldberger Coelho e Plínio Martins Filho. São Paulo: Perspectiva, 1953.

MARCELINO, Douglas Átila. Historiografia, morte e imaginário: Estudo sobre racionalidades e sensibilidades políticas. São Paulo: Alameda, 2017.

ORLANDI, Eni. Análise de Discurso: Princípios e procedimentos. $4^{\mathrm{a}}$. ed. Campinas/SP: Pontes Editores, 2002.

RANCIÉRE, Jacques. Os nomes da História: um ensaio de poética do saber. Trad. Eduardo Guimarães e Eni Orlandi. São Paulo: Educ., 1994.

Texto-imagem 01: Disponível em:

<https://www.missedinhistory.com/podcasts/ ines-de-castro.htm $>$;

<https://upload.wikimedia.org/wikipedia/ commons / thumb/3/31/Jacente_ do_t $\%$ C $3 \%$ BAmulo_de_D._In $\%$ C 3 $\%$ AAs_de_ Castro.png/240pxJacente_do_t $\%$ C $3 \%$ BAmulo_ de_D._In $\%$ C3\%AAs_de_Castro.png $>$;

<https:/ / www.youtube.com/watch?v $=$ dhwACGBFzI>. Acesso em: 11/01/2017.

Submissão em 10 de janeiro de 2018

Aceito em 18 de janeiro de 2018. 